Article

\title{
Screen-Printed Voltammetric Biosensors for the Determination of Copper in Wine
}

\author{
Liliana Norocel ${ }^{1, *(1)}$ and Gheorghe Gutt ${ }^{2}$ \\ 1 Department of Health and Human Development, Stefan cel Mare University of Suceava, 13, \\ University Street, 720229 Suceava, Romania \\ 2 Faculty of Food Engineering, Stefan cel Mare University of Suceava, 13, University Street, \\ 720229 Suceava, Romania; g.gutt@fia.usv.ro \\ * Correspondence: liliana.norocel@fia.usv.ro
}

Received: 29 August 2019; Accepted: 20 October 2019; Published: 24 October 2019

\begin{abstract}
Certain heavy metals present in wine, including copper, can form insoluble salts and can induce additional casse, so their determination is important for its quality and stability. In this context, a new biosensor for quantification of copper ions with BSA protein (bovine serum albumin) and using SPE electrodes (screen-printed electrodes) is proposed. The objective of this research was to develop a miniaturized, portable, and low-cost alternative to classical methods. A potentiostat, which displays the response in the form of a cyclic voltammogram, was used in order to carry out this method. Values measured for the performance characteristics of the new biosensor revealed a good sensitivity $\left(21.01 \mu \mathrm{A} \mathrm{mM}^{-1} \mathrm{~cm}^{-2}\right)$, reproducibility $(93.8 \%)$, and limit of detection $(0.173 \mathrm{ppm})$, suggesting that it has a high degree of application in the analysis proposed by our research. The results obtained for wine samples were compared with the reference method, atomic absorption spectrometer (AAS), and it was indicated that the developed biosensor is efficient and can be used successfully in the analysis of copper in wine. For the 20 samples of red wine analyzed with AAS, the concentration range of copper was between 0.011 and $0.695 \mathrm{mg} / \mathrm{L}$ and with the developed biosensor it was between 0.037 and $0.658 \mathrm{mg} / \mathrm{L}$. Similar results were obtained for the 20 samples of white wine, $0.121-0.765 \mathrm{mg} / \mathrm{L}$ (AAS) and 0.192-0.789 mg/L (developed biosensor), respectively.
\end{abstract}

Keywords: wine safety; heavy metal; copper casse

\section{Introduction}

The presence of metallic contaminants in wines is attributed to many endogenous and exogenous factors. The mineral content of wine depends on soil, location, grape varieties, weather or environmental conditions, and wine practices [1]. The main source may be the vineyard sprays and particularly the use of Bordeaux mixture (a copper-based vineyard spray), which significantly contributes to high levels of copper ions in the must (in excess of $20 \mathrm{mg} / \mathrm{L}$ in two cases investigated by the Australian Wine Research Institute). However, fermentation usually eliminates much of this excess through binding of the metal to yeast and removal with the lees. Another source would be the contact of a wine with copper or copper alloys during winemaking; furthermore, the addition of copper sulfate to correct sulfidic off-odors is arguably a major cause of copper instability. Certain heavy metals, including copper, can form insoluble salts and can induce additional casse [2]. The presence of copper in high concentration in wine causes the so-called copper casse, which can already be installed at concentrations of $0.5 \mathrm{mg} \mathrm{Cu} / \mathrm{L}$, having a negative effect on the organoleptic properties of the wine [1]. Excess of copper ions determined before bottling can be removed from the wine by the addition of potassium ferrocyanide. Therefore, by avoiding wine quality degradation, the determination of these ions has economic benefits for wine producers. Nowadays, most existing methods used for heavy metal trace analysis 
include spectrophotometric (AAS—atomic absorption spectrometer, ICP/MS—inductively coupled plasma mass spectrometry, ICP/AES - inductively coupled plasma atomic emission spectrometry), voltammetric, and chromatographic methods, which can detect analytes at very low concentrations. However, all these classic techniques are generally costly and laborious, so it is necessary to develop new methods that eliminate these disadvantages. Biosensor systems are relatively recent achievements that allow rapid, inexpensive, and in situ quantitative analytical determinations, providing solutions for food analysis in terms of specificity and time savings [3]. Electrochemical biosensors are often preferred due to simplicity and miniaturization. From this point of view, the use of screen-printed electrodes not only solves the problem of cost efficiency, but also satisfies the portability requirement, contributing to the progress towards decentralized analysis. There are numerous studies on the detection of copper ions with biosensors by the specified means, but most of them are developed around the analysis of these ions in water or foods [4-8]. Only a few studies can be applied in the determination of the copper content of wine, despite the fact that the presence of this element has a great impact on the quality and safety of this product [2,9]. Numerous scientific papers studied the use of bovine serum albumin (BSA) in terms of the mechanism of adsorption and the interactions of the protein with different electrode materials. A series of investigations were particularly focused on the interactions between BSA and copper; these studies are useful for understanding the biological phenomena related to the formation of covalent bonds [10-12]. Several investigations used the metal-protein interaction to design electrodes for electrochemical detection of heavy metals [13]. An interesting experiment regarding the binding of $\mathrm{Cu}$ (II) ion to BSA was achieved by ion-selective electrode potentiometry, and the results offered more attractive features than some traditional methodologies [14]. The immobilization of proteins on the electrode is important for the development and performance of biosensors and has been investigated in numerous studies [15-19]. The characterization of metal binding to metalloproteins is vital for our understanding of the relationship between structure and function. Fundamental for metal binding activity is the intrinsic binding constant, which is a parameter that describes the affinity with which metal ions are bound to specific protein sites. The central tenet of the strategy is the presentation of the metal to the protein in the form of well-characterized, low-molecular-weight chelates to prevent metal hydrolysis and nonspecific binding. Further, this strategy permits the determination of the number of specific metal binding sites and provides insights into the amino acid ligands involved in binding [20]. Among the immobilization methods applied for the specified recognition element, a simple method is photoreactive immobilization, performed by benzophenone irradiation at the $350 \mathrm{~nm}$ wavelength [21-24]. Benzophenone $\left(\mathrm{Ph}_{2} \mathrm{CO}\right)$ is activated by UV light in the range $350-360 \mathrm{~nm}$, and its reaction mechanism is as follows: The carbonyl oxygen forms a ketyl radical when exposed to UV light and then abstracts the hydrogen from a $\mathrm{C}-\mathrm{H}$ bond in a nearby molecule, followed by $\mathrm{C}-\mathrm{C}$ bond formation between $\mathrm{Ph}_{2} \mathrm{CO}$ and the attacked molecule. Advantages of $\mathrm{Ph}_{2} \mathrm{CO}$ include chemical stability, activation in a UV range that does not damage proteins or cells, and stability in ambient light [25]. The purpose of this study was to develop a biosensor with practical significance for determining the copper content of wine, using as biological element, BSA protein, immobilized by a photoreactive compound, namely benzophenone, and an electrochemical transducer providing a cyclic voltammogram response. Furthermore, the results obtained by the voltammetric method for 40 wine samples were compared with the reference method, namely AAS (atomic absorption spectrometer), to confirm the efficiency of the developed electrochemical biosensor. The novelty of this biosensor is a new method to determine copper ions in wine which solves the problem of high cost and portability.

\section{Materials and Methods}

\subsection{Reagents}

Standard protein (200 mg BSA/mL), benzophenone (99\%), ethanol (98\%), ammonium acetate, and copper sulfate were purchased from Sigma-Aldrich (Steinheim, Germany). Screen-printed electrodes (SPE) were purchased from Pine Research (Durham, NC, USA) and include a carbon 
working electrode with a $2.0 \mathrm{~mm}$ diameter, a carbon counter electrode, and a silver/silver chloride $(\mathrm{Ag} / \mathrm{AgCl})$ reference electrode. The SPE dimensions are $15 \times 61 \times 0.36 \mathrm{~mm}$, type RRPE1001C.

\subsection{Samples}

In this study, 40 wine samples (20 samples of red wine and 20 samples of white wine) from different local producers from Vrancea County, Romania were analyzed by voltammetric method. The results obtained were compared with the AAS values of the same samples.

\subsection{Electrochemical Measurements}

The electrochemical measurements were performed with a Metrohm Autolab potentiostat/galvanostat, PGSTAT204 (Metrohm Autolab B.V., Utrecht, The Netherlands), controlled by NOVA 2.1 software. The testing conditions were as follows: Starting potential $0.6 \mathrm{~V}$, switching potential $-0.53 \mathrm{~V}$, scanning rate $0.1 \mathrm{~V} / \mathrm{s}$, and frequency $100 \mathrm{~Hz}$.

The electrode is immersed in undiluted wine while a potential is applied. This allows the deposition on the electrode surface of the loosely bound fraction of $\mathrm{Cu}$ from the wine to form a copper-protein complex. After the electrode is typically immersed in wine for 1, 90, and $180 \mathrm{~s}$, the electrode is washed with $60 \%$ aqueous ethanol and then $4.0 \mathrm{M}$ ammonium acetate. The potential of the electrode is then allowed to increase and, at a potential characteristic of copper ions, the resulting cyclic voltammogram is obtained.

For the cyclic voltammetric analysis of the copper concentration in wine it was not necessary to prepare samples, but it was only used at a temperature of $14{ }^{\circ} \mathrm{C}$.

\subsection{Atomic Adsorption Spectrometry}

Spectrophotometric analyses were recorded using the atomic absorption spectrometer (AAS), Schimadzu AA 6300, according to "Compendium of International Methods of Analysis". The sample preparation procedure for copper ion determination was simple and involved dilution: A $20 \mathrm{~mL}$ wine sample was placed in a $100 \mathrm{~mL}$ volumetric flask and the volume was made up to $100 \mathrm{~mL}$ with double-distilled water. The dilution was modified for some samples to obtain a response within the dynamic range of the detector. The absorbance was measured at $324.8 \mathrm{~nm}$ [26].

\subsection{Scanning Electron Microscopic Analysis}

The microscopic analysis of the working electrode before immobilization, after immobilization, and after use in the copper solution was performed with a VEGA II LMU scanning electron microscope (TESCAN, Czech Republic).

\subsection{Immobilization of Biological Element on SPE and Development of Biosensor}

An immobilization of the biological element with benzophenone was carried out in the presence of ultraviolet light; the element was fixed to the working electrode at a wavelength of $350 \mathrm{~nm}$. Then, $1 \mu \mathrm{L}$ of standard protein solution ( $200 \mathrm{mg} \mathrm{BSA} / \mathrm{mL}$ ) and $1 \mu \mathrm{L}$ benzophenone solution $5 \%$ were pipetted on the surface of the working electrode of the SPE. The immobilization occurred together (BSA and $\mathrm{Ph}_{2} \mathrm{CO}$ ) under the influence of ultraviolet radiation for $20 \mathrm{~min}$, then the miniaturized electrode was introduced into a cell with $10 \mathrm{~mL}$ of sample and analyzed by cyclic voltammetry.

\subsection{Statistical Analysis}

Descriptive statistics (standard deviation, coefficient of variation) and the graphs were performed with Origin 8E (OriginLab Corporation, Northampton, MA, USA) software. 


\section{Results}

The developed biosensor was based on the following processes: The use of BSA as a biologically active element for the selection of copper ions, photochemical immobilization with benzophenone by irradiation under UV light, and analysis of copper content using these modified screen-printed electrodes with a potentiostat that provides a response in the form of a cyclic voltammogram.

The quantitative analysis of the interaction between copper (II) complexes and bovine serum albumin was undertaken by cyclic voltammetry. These interactions between BSA and copper represent a whole biological phenomenon related to the formation of covalent bonds. Studies of the behavior of BSA have shown a greater affinity for the first copper (II) ion than for those subsequently bound. The binding site for this first copper ion seems to include the amino-terminal position as Peters and Blumenstock have specified [27].

In order to obtain a calibration curve from the cyclic voltammograms, copper solutions (0.2, $0.4,0.6,0.8$, and $1 \mathrm{mg} / \mathrm{L}$ ) were used. The concentration was reported at the maximum current density for each solution because the anodic and cathodic peaks are extremely small. For recording possible changes of the maximum current occurring with time, for the same concentrations of copper, cyclic voltammograms were also performed but analyzed after 90 and $180 \mathrm{~s}$ from the time of insertion of the SPE electrode into the cell with solution (Figure 1).

The NOVA 2.1 software was used for the measurement of the current obtained from the resulted voltammograms, the maximum and minimum intensity values were extracted and used to perform the calibration curves that are shown in Figure 2a. For the specific cyclovoltagrams (with the reduction potential of copper and the Cu-BSA complex), necessary to characterize the performances of the sensor, the option of the triangular signal was selected from the software so that the interpretation of the voltammograms could be realized at the maximum reduction potential $(0.6 \mathrm{~V})$. This potential for copper reduction is known from the electrochemical literature and is also on the scale of Nernst potentials. After 180 s, cyclovoltagrams the highest $R^{2}(0.94)$ was observed, while the lowest value of $R^{2}(0.80)$ resulted for cyclic voltammograms performed immediately after the introduction of the electrode into the cell. The highest value of $\mathrm{R}^{2}$ at $180 \mathrm{~s}$ may be the result of a stability increase of the solution in time. Furthermore, depending on the amount of copper present in the solution $(10 \mathrm{~mL})$, the mass deposited on the electrode during the electrochemical measurements was calculated according to Faraday's law, and the resulting quantities are presented in Figure $2 b$.

The highest quantities of copper detected with the biosensor were for the electrodes analyzed immediately after the introduction of the electrode into the cell, showing that the evolution in time was not favorable in the sense that the quantities of deposed copper on the SPE were reduced.

The results obtained for the 20 samples of red wine by voltammetric method and the AAS method are presented in Figure 3.

It can be observed that the differences between the two methods were small enough to recommend the use of the voltammetric method in wine analysis. The effect of $\mathrm{pH}$ on the voltammetric response of $\mathrm{Cu}$ (II) is well known by the fact that at a lower $\mathrm{pH}$, both the cathodic and anodic peak current are high. Therefore, with the increase of $\mathrm{pH}$, the cathodic and the anodic peak current gradually decrease [28]. This is probably the cause of the higher selectivity of the new method developed, in the case of red wines that have a lower $\mathrm{pH}$ (3.29-3.38) than the white wines analyzed (3.59-3.76). The differences between the two methods are more visible for white wine than for red wine, which confirms this assumption.

Another remark was that from the results of 20 samples of white wine analyzed with the developed biosensor, 14 samples had higher values than the AAS method, suggesting that this biologic element may select from the matrix of wine compounds another ion that interferes with copper. Similar, in the case of red wines, of the 20 samples analyzed with the biosensor, 13 samples indicated a higher copper concentration than the AAS reference method. The mean percentage recovery for the repeated analysis was calculated from difference of results obtained with AAS and biosensor depending on the type of wine, and it was about $98.69 \%$ for white wine and $96.30 \%$ for red wine. The coefficient of variation 
calculated for the results of two methods was between 0.6 and 3.7 for the red wine and between 0.9 and 1.72 for white wine.

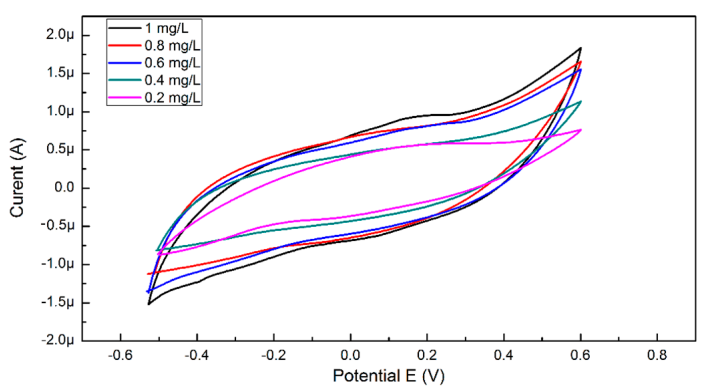

(a)

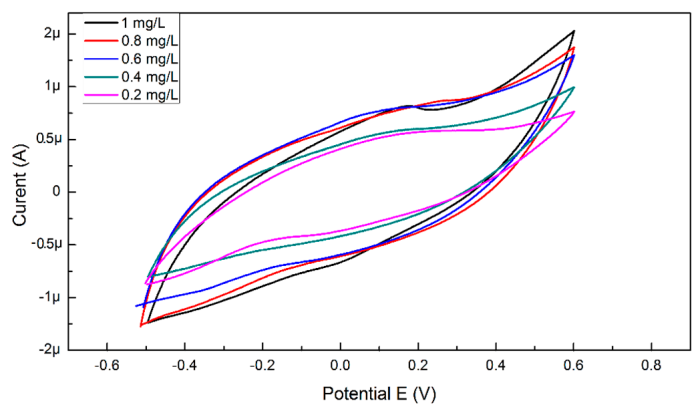

(b)

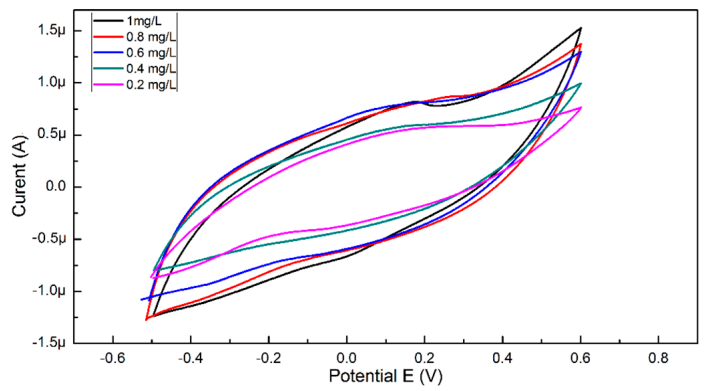

(c)

Figure 1. The cyclic voltammogram obtained for the five copper solutions, (a) analyzed voltammetrically immediately after the introduction of the electrode into the cell, (b) after $90 \mathrm{~s}$ from the introduction of the electrode into the cell, (c) after $180 \mathrm{~s}$ from the introduction of the electrode into the cell.
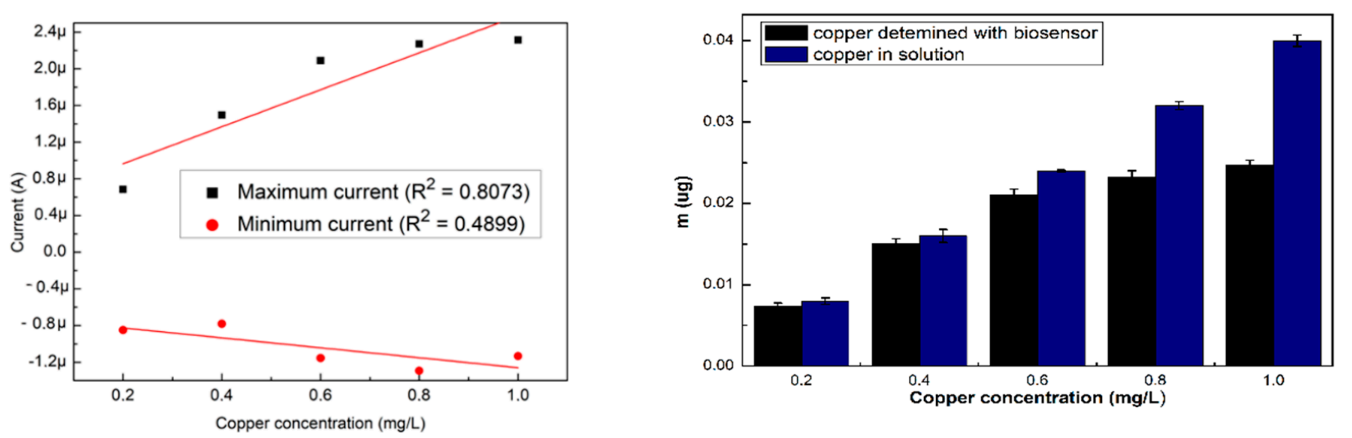

Figure 2. Cont. 

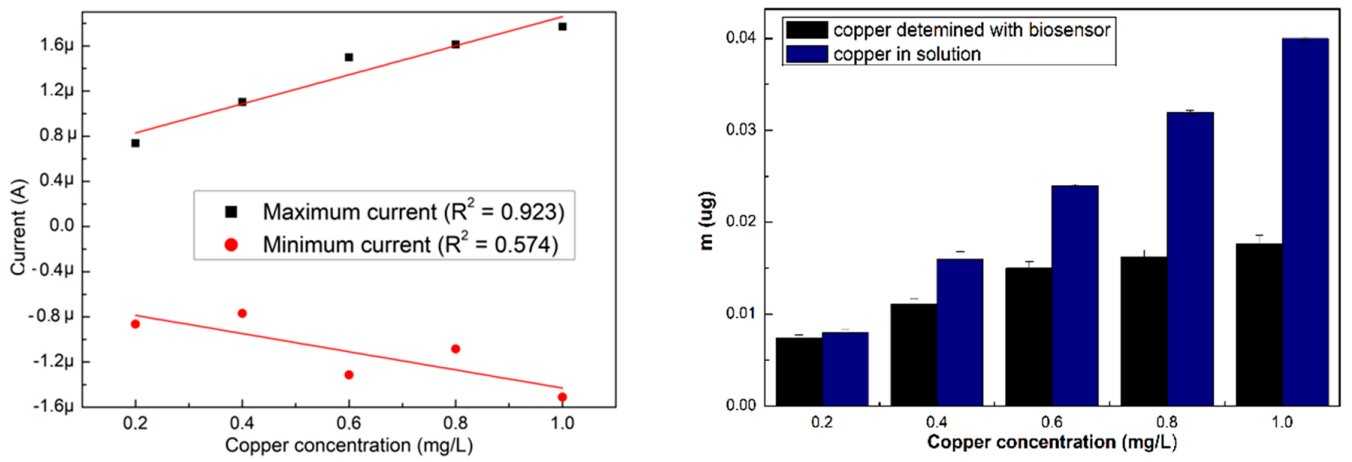

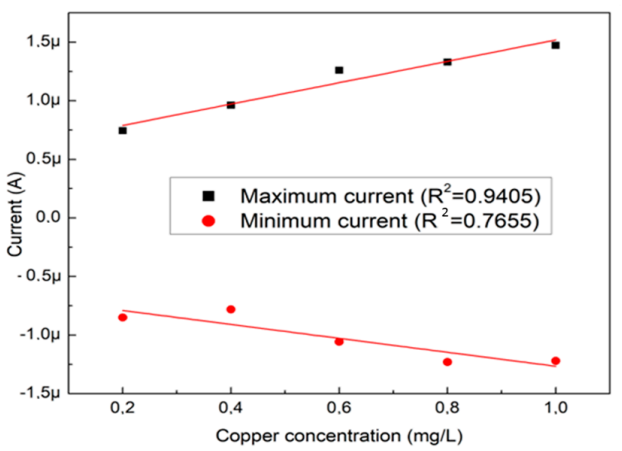

(a)

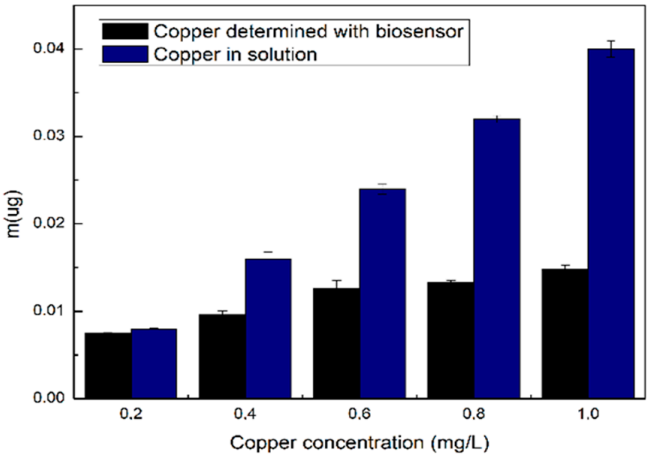

(b)

Figure 2. (a) Variation of the maximum and minimum intensity of the three voltammograms, and (b) amount of labile copper deposited on the SPE, depending on the existing copper concentration. All the analyses were carried out in triplicate.
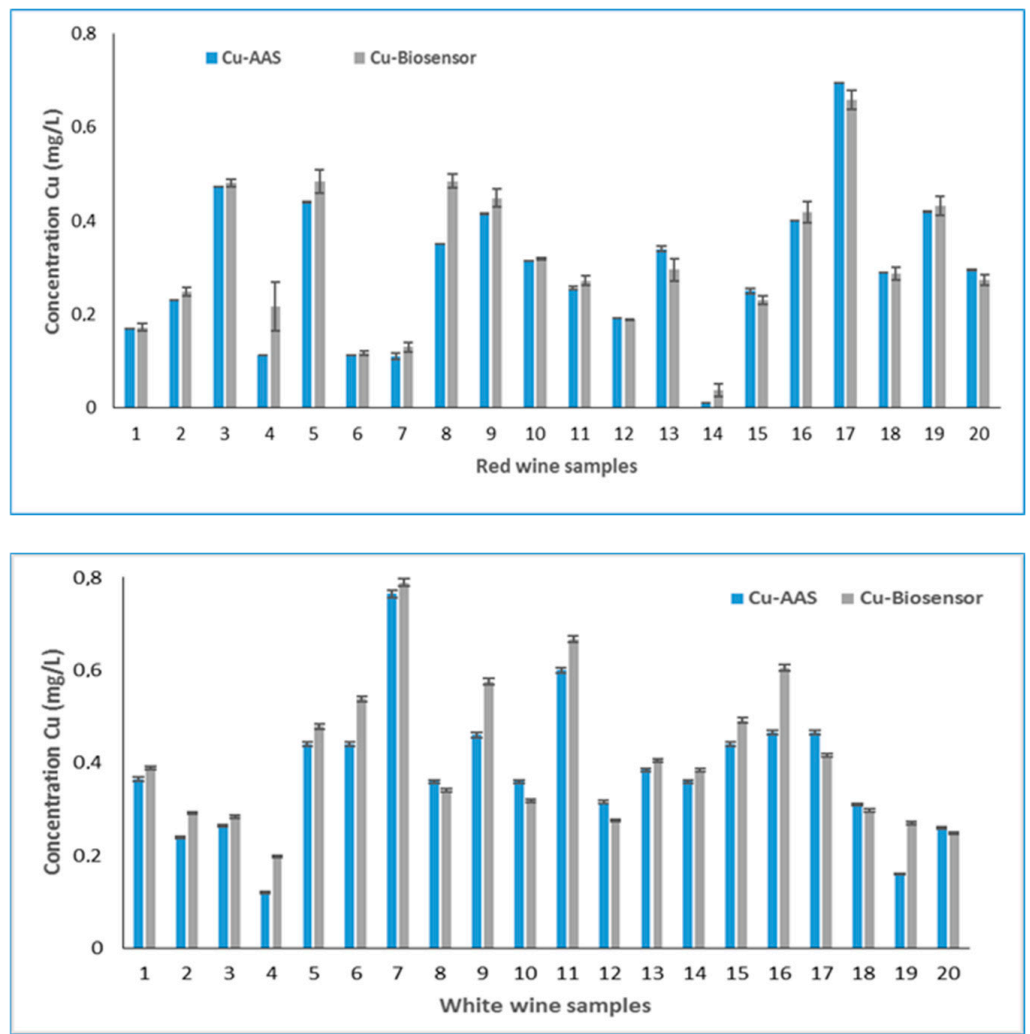

Figure 3. Concentrations of labile copper in red and white wine. 

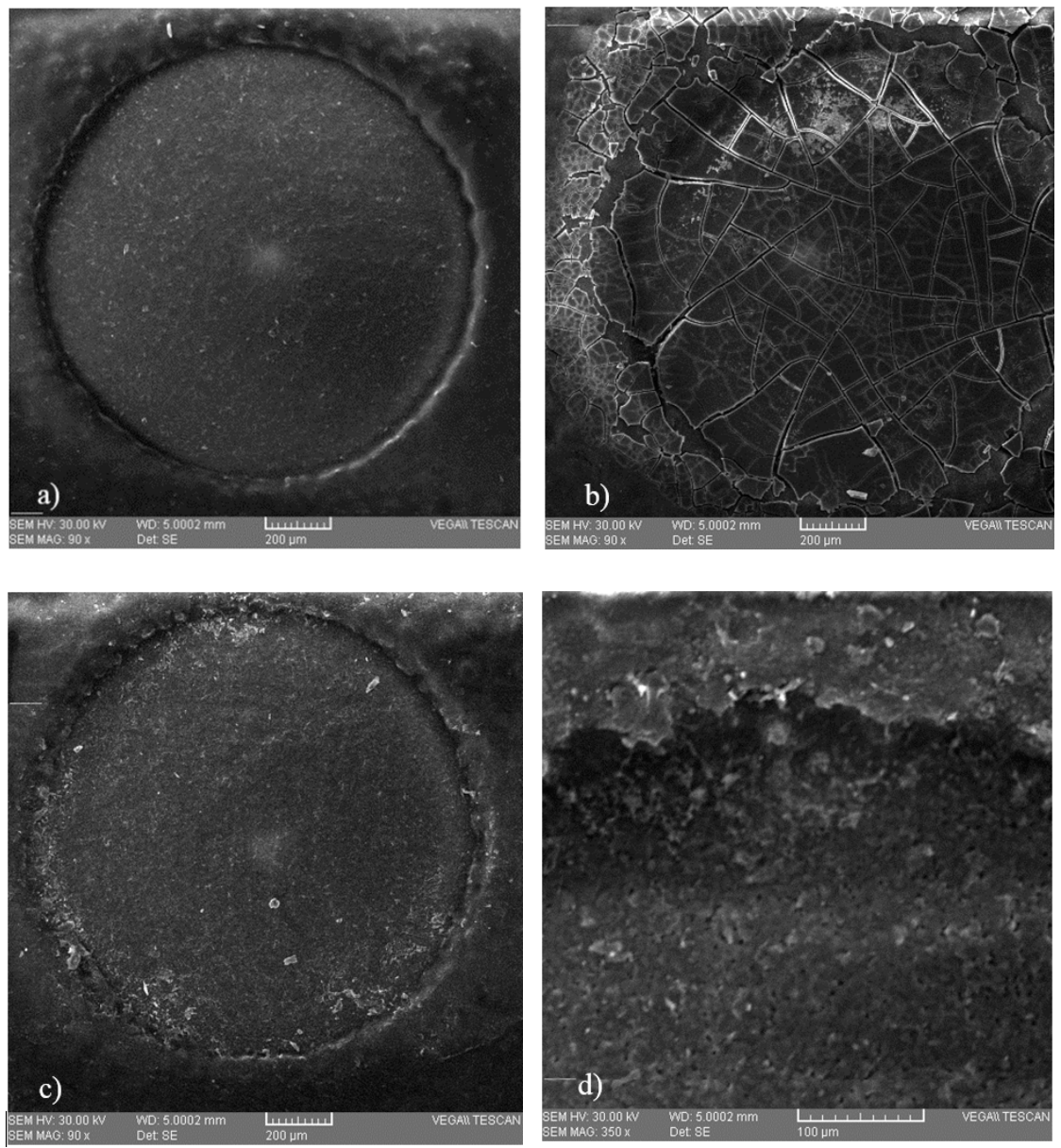

Figure 4. Microscopic images of the surface of the working electrode of (a) a screen-printed electrode (SPE) that was not used, (b) a SPE containing immobilized bovine serum albumin (BSA), and (c) a SPE that was introduced into a $0.6 \mathrm{mg} / \mathrm{L}$ copper solution, with a close-up (d) obtained at a magnification of $350 \times$.

Microscopic analysis (Figure 4) was performed in order to observe possible deposition on the surface of three SPE electrodes, on an unused electrode, on the surface of an electrode after immobilization of the protein, and on an electrode that was introduced into a copper solution of $0.6 \mathrm{mg} / \mathrm{L}$, respectively. These microscopic images show that some deposits of copper occurred, which means that this method is viable.

\section{Analytical Performance of the Biosensor}

The analytical performances of the biosensor were evaluated by sensitivity, detection limit, and biosensor response time.

Sensitivity was calculated using Equation (1) shown below:

$$
\text { Sensitivity }=\frac{m}{A}
$$

where $m$-slope of calibration curve $\left(\mu \mathrm{A} \mathrm{mM}^{-1}\right), A$-area of active surface $\left(\mathrm{cm}^{2}\right)$ [29].

The detection limit of blank sample (LoB), Equation (2), and the limit of detection (LoD) of the proposed biosensors are terms used to describe the lowest concentration of an analyte that can be reliably measured by an analytical procedure.

$$
\text { LoB }=\text { meanblank }+(\text { SDblank }),
$$


where $S D$ —standard deviation.

The LoD (Equation (3)) was determined by using the measured limit of blank sample (LoB) and the standard deviation of the lowest sample concentration [30,31]:

$$
L o D=L o B+(\text { SDlow concentration sample }) \text {. }
$$

The biosensor response time could be influenced by kinetic parameters, diffusion barriers, protein quantity, protein activity, and immobilization procedure [32].

Biosensor reproducibility was studied by measuring the copper-generated current of $0.6 \mathrm{mg} / \mathrm{L}$ in $10 \mathrm{~mL}$ deionized water. The biosensor was tested on three different days with a triple analysis $(\mathrm{n}=3)$. The total mean value was calculated and the relative standard deviation (RSD) provided analytical precision, and, after $90 \mathrm{~s}$ from the introduction of the electrode into the cell, the resulted reproducibility was $93.8 \%$. The resulting values of the performance characteristics of the biosensor are shown in Figure 5.

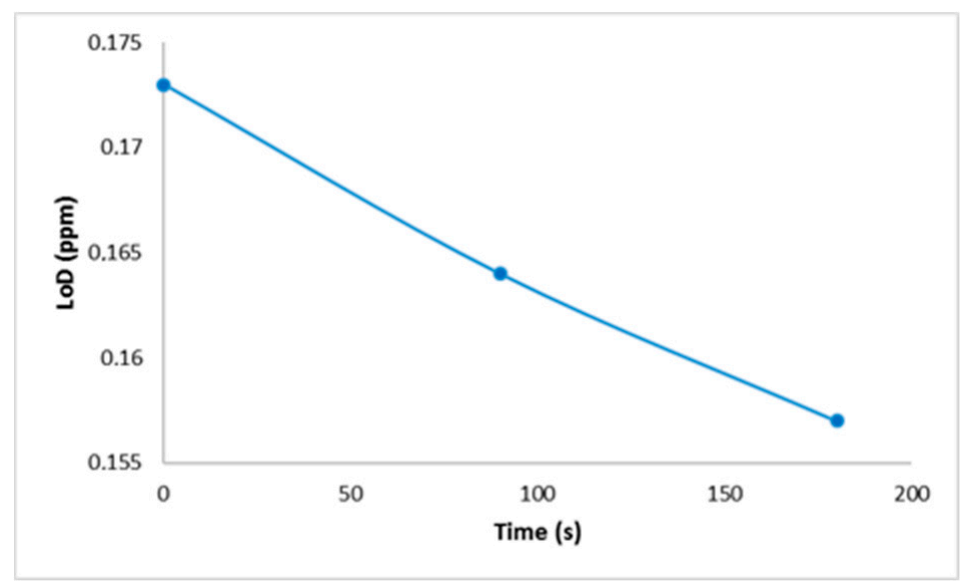

(a)

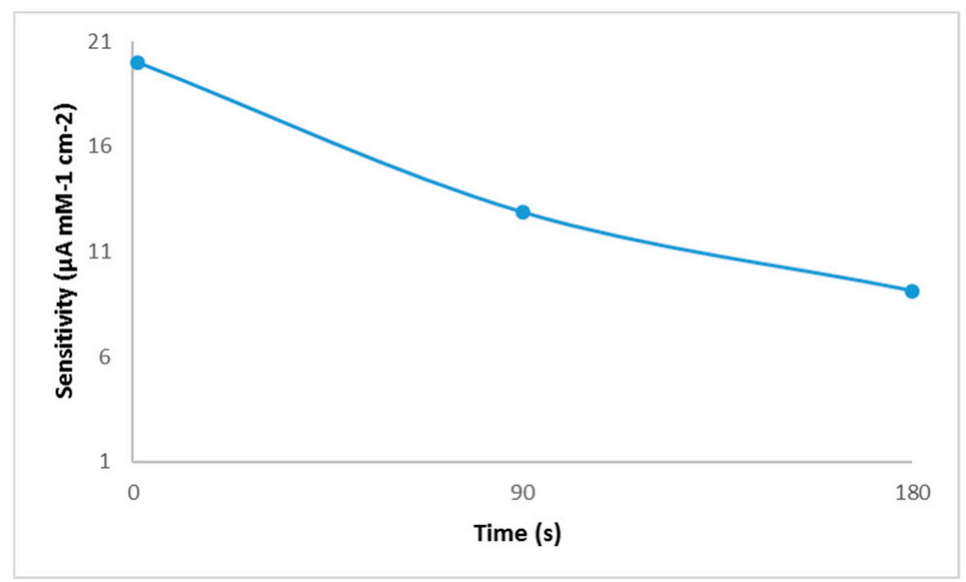

(b)

Figure 5. Cont. 


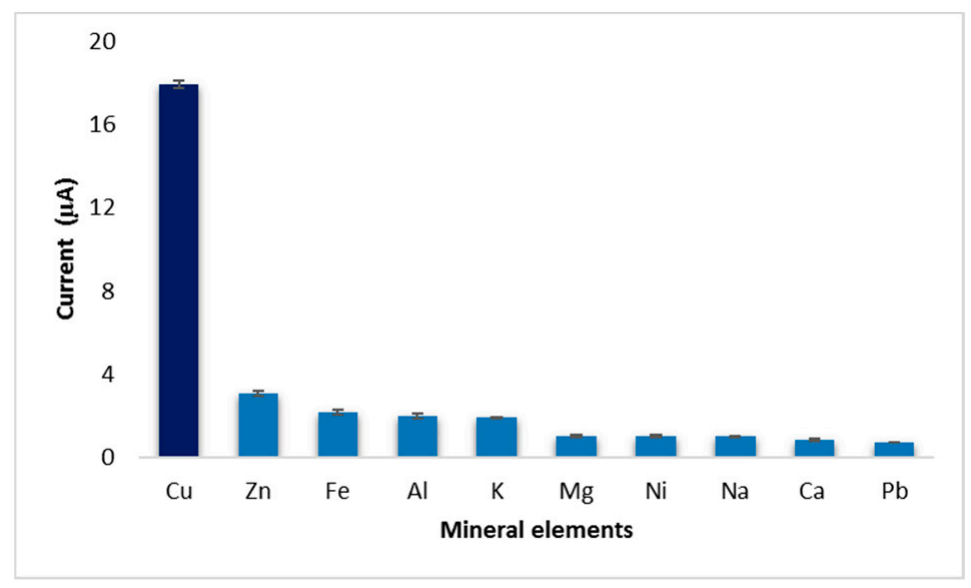

(c)

Figure 5. Performance characteristics of the biosensor: (a) limit of detection, (b) sensitivity, and (c) selectivity evaluation of the developed biosensor against the interference of mineral elements present in wine.

\section{Discussion}

Following the analysis of the copper solutions, higher linear regression values (0.94) were obtained after $180 \mathrm{~s}$ of immersion of the electrode and lower values (0.80) for cyclic voltammograms performed immediately after the electrode was inserted into the cell. This phenomenon could explain an increase in the stability of the solution over time. Although, the values of linear regression proved to be better in the case of analyses after $180 \mathrm{~s}$, the calculation of the amount of copper deposited on the electrode proved to be more favorable for those which were analyzed voltammetrically immediately after the introduction of the electrode into the cell. By comparing the developed method with the existing reference method, similar values were observed for both white and red wines. Additionally, this comparison shows that the differences between the two methods were small enough to recommend the use of the voltammetric method in wine analysis. Another evidence that confirms the viability of this new method is provided by the microscopic images that show some copper deposits. Regarding the analytical performance of the biosensor, the highest value of the resulting sensitivity was determined in the case of the sample analyzed when the electrode was introduced into the solution, and it decreased from the time of immersion to the time of the voltammetric analysis. The evolution of the detection limit values with time was the opposite, a fact that brings a major advantage to the performance of the biosensor. The resulting values of LoD were similar to those obtained by other authors [33]. The results of selectivity evaluation of the developed biosensor against the interference of minerals in wine prove that this new method has a good selectivity. Of the minerals analyzed, zinc has a got the highest level detected, which was expected since previous studies indicated its ability of binding to bovine serum albumin [21].

\section{Conclusions}

The results obtained of the proposed biosensor for determining copper ion concentration in wine have proven to be effective both for the performance characteristics and for comparing the results with the reference method. In the experimental part of the study, the biological element used showed good selectivity for the target analyte, and also indicated sensitivity and a detection limit that could recommend it as a possible means for the quantification of copper ions in wine. Therefore, the developed biosensor solves the real problem in quantifying copper ions, having in view that the present methods are laborious, expensive, and cannot be used in in situ analyses.

Author Contributions: Conceptualization, G.G. and L.N.; methodology, L.N.; software, L.N.; validation, G.G. and L.N.; formal analysis, L.N.; investigation, L.N.; resources, L.N.; data curation, L.N.; Writing-Original Draft 
preparation, L.N.; Writing_Review and Editing, G.G.; visualization, L.N.; supervision, G.G.; project administration, L.N.; funding acquisition, L.N.

Funding: This work was supported by contract no. 18PFE/16.10.2018 funded by the Ministry of Research and Innovation within Program 1-Development of national research and development system, Subprogram 1.2-Institutional Performance - RDI excellence funding projects.

Conflicts of Interest: The authors declare no conflict of interest.

\section{References}

1. Kailas, H.K. Analysis of iron and copper from wine samples. WJPPS 2015, 4, 2229-2233.

2. Rousseva, M.; Kontoudakis, N.; Schmidtke, L.M.; Scollary, G.R.; Clark, A.C. Impact of wine production on the fractionation of copper and iron in Chardonnay wine: Implications for oxygen consumption. Food Chem. 2016, 203, 440-447. [CrossRef] [PubMed]

3. Da Costa Silva, L.M.; Dos Santos, V.P.S.; Salgado, A.M.; Pereira, K.S. Biosensors for contaminants monitoring in food and environment for human and environmental health. In State of the Art in Biosensors-Environmental and Medical Applications; InTech: London, UK, 2013.

4. Vopálenská, I.; Váchová, L.; Palková, Z. New biosensor for detection of copper ions in water based on immobilized genetically modified yeast cells. Biosens. Bioelectron. 2015, 72, 160-167. [CrossRef] [PubMed]

5. Wang, R.; Wang, W.; Ren, H.; Chae, J. Detection of copper ions in drinking water using the competitive adsorption of proteins. Biosens. Bioelectron. 2014, 57, 179-185. [CrossRef] [PubMed]

6. Feier, B.; Băjan, I.; Fizeșan, I.; Floner, D.; Cristea, C.; Geneste, F.; Săndulescu, R. Highly Selective Electrochemical Detection of Copper(II) Using N, N'-bis (acetylacetone) ethylenediimine as a Receptor. Int. J. Electrochem. Sci. 2015, 10, 121-139.

7. Masullo, T.; Puccio, R.; Di Pierro, M.; Tagliavia, M.; Censi, P.; Vetri, V.; Colombo, P. Development of a biosensor for copper detection in aqueous solutions using an anemonia sulcata recombinant GFP. Appl. Biochem. Biotechnol. 2014, 172, 2175-2187. [CrossRef] [PubMed]

8. See, W.P.; Nathan, S.; Lee, Y.H. A disposable copper(II) ion biosensor based on self-assembly of L-cysteine on gold nanoparticle-modified screen-printed carbon electrode. J. Sens. 2011, 2011, 230535.

9. Da Costa, A.S.; Delgadillo, I.; Rudnitskaya, A. Detection of copper, lead, cadmium and iron in wine using electronic tongue sensor system. Talanta 2014, 129, 63-71. [CrossRef]

10. Pinto, E.M.; Soares, D.M.; Brett, C.M. Interaction of BSA protein with copper evaluated by electrochemical impedance spectroscopy and quartz crystal microbalance. Electrochim. Acta 2008, 53, 7460-7466. [CrossRef]

11. Topală, T.; Bodoki, A.; Oprean, L.; Oprean, R. Bovine serum albumin interactions with metal complexes. Clujul Med. 2014, 87, 215-219. [CrossRef]

12. Asaturian, R.A. Cu (II)-BSA complexes and their identification by the ESR method. Gen. Physiol. Biophys. 1986, 5, 105-108. [PubMed]

13. Anicai, L.; Stoica, C.; Vladut, C.; Negru, A.; Teulon, J.M.; Odorico, M.; Enachescu, M. Synthesis and Characterization of a Novel Screen-Printed Modified Gold Electrode with Applications in Uranyl Ions Detection. Rev. Chim. 2015, 66, 1639-1644.

14. Liu, J. Investigation of $\mathrm{cu}$ (II) binding to bovine serum Albumin by potentiometry with an iron selective electrode: A biophysical chemistry experiment for the undergraduate curriculum. J. Chem. Educ. 2004, 81, 395. [CrossRef]

15. Pagán, M.; Suazo, D.; Del Toro, N.; Griebenow, K. A comparative study of different protein immobilization methods for the construction of an efficient nano-structured lactate oxidase-SWCNT-biosensor. Biosens. Bioelectron. 2015, 64, 138-146. [CrossRef] [PubMed]

16. Ley, C.; Holtmann, D.; Mangold, K.M.; Schrader, J. Immobilization of histidine-tagged proteins on electrodes. Colloids Surf. B Biointerfaces 2011, 88, 539-551. [CrossRef] [PubMed]

17. Ferrero, V.E.; Andolfi, L.; Di Nardo, G.; Sadeghi, S.J.; Fantuzzi, A.; Cannistraro, S.; Gilardi, G. Protein and electrode engineering for the covalent immobilization of P450 BMP on gold. Anal. Chem. 2008, 80, 8438-8446. [CrossRef] [PubMed]

18. Trashin, S.; de Jong, M.; Meynen, V.; Dewilde, S.; De Wael, K. Attaching Redox Proteins onto Electrode Surfaces by using bis-Silane. ChemElectroChem 2016, 3, 1035-1038. [CrossRef] 
19. Scouten, W.H.; Luong, J.H.; Brown, R.S. Enzyme or protein immobilization techniques for applications in biosensor design. Trends Biotechnol. 1995, 13, 178-185. [CrossRef]

20. Masuoka, J.; Saltman, P. Zinc (II) and copper (II) binding to serum albumin. A comparative study of dog, bovine, and human albumin. J. Biol. Chem. 1994, 269, 25557-25561.

21. Ratner, B.D.; Hoffman, A.S.; Schoen, F.J.; Lemons, J.E. Biomaterials Science: An Introduction to Materials in Medicine; Elsevier Academic Press: San Diego, CA, USA, 2004.

22. WanTai, G. Protein immobilization on polypropylene surface modified by photografting. J. Beijing Univ. Chem. Technol. (Nat. Sci. Ed.). 2008, 4, 014.

23. Hwang, L.Y.; Götz, H.; Hawker, C.J.; Frank, C.W. Glyco-acrylate copolymers for bilayer tethering on benzophenone-modified substrates. Colloids Surf. B Biointerfaces 2007, 54, 127-135. [CrossRef] [PubMed]

24. Wu, X.; Tang, Q.; Liu, C.; Li, Q.; Guo, Y.; Yang, Y.; Deng, Y. Protein photoimmobilizations on the surface of quartz glass simply mediated by benzophenone. Appl. Surf. Sci. 2011, 257, 7415-7421. [CrossRef]

25. Ericsson, E. Biosensor Surface Chemistry for Oriented Protein Immobilization and Biochip Patterning. Ph.D. Thesis, Linköping University, Linkoping, Sweden, 2013.

26. Organisation Internationale de la Vigne et du Vin. Compendium of International Methods of Analysis-OIV, Copper, OIV-MA-AS322-06: R2009, Method OIV-MA-AS322-06, Type IV Method, Copper (Resolution Oeno 377/2009). Available online: http://www.oiv.int/en/technical-standards-and-documents/methodsof-analysis/compendium-of-international-methods-of-analysis-of-wines-and-musts-2-vol (accessed on 22 October 2019).

27. Peters, T.; Blumenstock, F.A. Copper-binding properties of bovine serum albumin and its amino-terminal peptide fragment. J. Biol. Chem. 1967, 247, 1574-1578.

28. Haque, F.; Rahman, M.S.; Ahmed, E.; Bakshi, P.K.; Shaikh, A.A. A cyclic voltammetric study of the redox reaction of $\mathrm{Cu}$ (II) in presence of ascorbic acid in different pH media. Dhaka Univ. J. Sci. 2013, 61, 161-166. [CrossRef]

29. Balakrishnan, S.R.; Hashim, U.; Letchumanan, G.R.; Kashif, M.; Ruslinda, A.R.; Liu, W.W.; Poopalan, P. Development of highly sensitive polysilicon nanogap with APTES/GOx based lab-on-chip biosensor to determine low levels of salivary glucose. Sens. Actuator A Phys. 2014, 220, 101-111. [CrossRef]

30. Armbruster, D.A.; Pry, T. Limit of blank, limit of detection and limit of quantitation. Clin. Biochem. Rev. 2008, 29, S49-S52.

31. Norocel, L.; Gutt, G. Development and performance testing of an electrochemical sensor for determination of iron ions in wine. Aust. J. Grape Wine R 2019, 25, 161-164. [CrossRef]

32. Alqasaimeh, M.; Heng, L.Y.; Ahmad, M.; Raj, A.S.; Ling, T.L. A large response range reflectometric urea biosensor made from silica-gel nanoparticles. Sensors 2014, 14, 13186-13209. [CrossRef]

33. Pathakoti, K.; Manubolu, M.; Hwang, H.M. Nanotechnology applications for environmental industry. In Handbook of Nanomaterials for Industrial Applications; Elsevier: Amsterdam, The Netherlands, 2018; pp. 894-907.

(C) 2019 by the authors. Licensee MDPI, Basel, Switzerland. This article is an open access article distributed under the terms and conditions of the Creative Commons Attribution (CC BY) license (http://creativecommons.org/licenses/by/4.0/). 